\title{
REPRESENTAÇÃO DAS LINGUAGENS SOCIAIS NO ROMANCE: DESENCONTRO CULTURAL E IDEOLÓGICO EMSÃO BERNARDO, DE GRACILIANO RAMOS
}

Maria Celina Novaes Marinho*

RESUMO: Neste trabalho, examina-se a representação da heterogeneidade discursiva no romance, tomando-se como objeto de análise o livro São Bernardo, de Graciliano Ramos.

Palavras-Chave: Bakhtin, romance, dialogismo, heterogeneidade discursiva.

Ao analisar o romance, Mikhail Bakhtin distingue duas linhas estilísticas na evolução européia desse gênero. $O$ romance da primeira linha nutrese da multiformidade dos gêneros extra-literários e semi-literários, mas tende a neutralizar as vozes sociais aí presentes com a adoção de uma linguagem uniformizada e "enobrecida" Na segunda linha estilística, as linguagens não-literárias são incorporadas ao romance sem sofrer um processo de "literaturização" Ou seja: essas linguagens entram no romance ainda contaminadas pelo diálogo social. (Bakhtin, 1988, 200-2)

É principalmente sobre a segunda linha estilística que Bakhtin desenvolve seus estudos. Para ele, o romance estrutura-se fundamentalmente sobre a representação da fala dos sujeitos e de seus universos ideológicos. No romance, não é a imagem do homem em si que importa, mas a imagem de sua linguagem (Bakhtin, 1988: 137). E, na tessitura dialogizada do discurso romanesco, o reconhecimento de uma linguagem realiza-se através de outra linguagem, o reconhecimento de uma concepção de mundo é feito através de outra concepção de mundo. É esta, segundo Bakhtin, a tarefa do romance: "o desmascaramento das linguagens sociais e das ideologias" (Bakhtin, 1988, 162).

Procurando abarcar a pluralidade de vozes sócio-ideológicas de uma época e ao mesmo tempo procurando mostrar como essas vozes dialogam, o

* Doutoranda do Departamento de Lingüística da FFLCH/USP. 

Desencontro cultural e ideológico em São Bernardo, de Graciliano Ramos. Língua e Literatura, n. 22, p. 123-135, 1996.

romance acaba por se colocar na berlinda, passando a mostrár também a sua própria crise de linguagem, enquanto gênero em formação. O movimento de autocrítica revela a luta entre o esforço de fixar uma forma, de inseri-la na tradição literária e, por outro lado, o deslocamento constante que significa a incorporação de novas linguagens - "estrangeiras", não-literárias - nesse gênero.

Mikhail Bakhtin observa ainda que o discurso romanesco da segunda linha só se tornou possível numa época em que "foram criadas condições ideais para a interação e o esclarecimento mútuo das linguagens, para a passagem do plurilingiuismo da sua "existência em si" (quando as linguagens não se conhecem ou podem ignorar-se) a uma "existência para si" (quando as linguagens do plurilingüismo se descobrem mutuamente e começam a servir de fundo dialógico uma às outras)"'(Bakhtin, 1988: 204).

É sob essa perspectiva que pensamos em analisar alguns aspectos da representação do diálogo social em São Bernardo, de Graciliano Ramos. Bakhtin observa que para construir um romance, mais do que dominar a linguagem literária, é necessário ao escritor ter conhecimento das linguagens do plurilingüismo social (Bakhtin, 1988: 163). Essa sempre foi uma das principais preocupações de Graciliano Ramos com relação ao fazer literário. É comum encontrar em suas cartas observações como esta:

"Pergunta-me se esta criatura deve falar como toda gente. Está claro. Pois havia de usar linguagem diferente? Falar como as pessoas, sem dúvida. Foi o palavreado difícil dos personagens sabidos demais que arrasou a antiga literatura brasileira" (Ramos, 1982: 161).

Comentário que sugere a importância da representação da fala dos sujeitos na concepção do romance. Ou ainda, esta outra observação:

"O São Bernardo está pronto, mas foi escrito quase todo em português, como você viu. Agora está sendo traduzido para o brasileiro, um brasileiro encrencado, muito diferente desse que aparece nos livros da gente da cidade, um brasileiro matuto" (Ramos, 1982: 135).

Esse outro comentário mostra o valor que Graciliano atribuía ao uso das linguagens sociais no romance. 
A "provação do discurso literário" a que se refere Bakhtin, aparece de modo bem claro em São Bernardo. Tendo pouca familiaridade com o mundo das letras, Paulo Honório utiliza na narração termos da sua linguagem, sertaneja; não deixa, contudo, de manifestar receio de que a sua linguagem e o seu modo de narrar não sejam adequados à prática literária:

"De bicho na capação (falando com pouco ensino), esperneei nas unhas do Pereira, que me levou músculo e nervo, aquele malvado" (Ramos, 1992: 13-4).

"Também pode ser que, habituado a tratar com matutos, não confie suficientemente na compreensão dos leitores e repita passagens insignificantes" (Ramos, 1992: 10).

Paulo Honório refere-se a uma linguagem e a uma composição romanescas já relativamente consolidadas e sente o risco de caminhar por veredas ainda não conhecidas. Parece constantemente se dividir entre o universo letrado de Madalena e o seu universo da comunicação oral, da fala direta, sem meias palavras. Mas, de qualquer modo, Paulo Honório não capitula à linguagem "enobrecida".

"As pessoas que me lerem terão, pois, a bondade de traduzir isto em linguagem literária, se quiserem. Se não quiserem, pouco se perde" (Ramos, 1992: 11).

A construção de um narrador que escapa ao padrão, como Paulo Honório, é parte da crítica que Graciliano Ramos faz ao artificialismo da linguagem literária, que a afasta do diálogo social (e, conseqüentemente, de todo o plurilingüismo que o constitui). A percepção das diferenciações sócio-lingüísticas está presente em toda a obra de Graciliano Ramos. Em suas obras, é possível ver de forma bastante clara os matizes da estratificação da linguagem (em gêneros, variantes lingüísticas, discursos de diferentes grupos sociais, etc.). Suas personagens aparecem quase sempre num processo de comunicação marcado pela diferença, seja cultural, seja ideológica. Nesse processo, a personagem toma consciência da linguagem do outro e do lugar relativo de sua própria linguagem.

Recapitulemos um pouco a estrutura do livro. São Bernardo é a narração que Paulo Honório faz de sua vida, procurando encontrar nela algum sentido. Nos dois primeiros capítulos, Paulo Honório - que tem pouco con- 

Desencontro cultural e ideológico em São Bernardo, de Graciliano Ramos. Língua e Literatura, n. 22, p. 123-135, 1996.

tato com o mundo das letras - expõe suas dificuldades para escrever o livro. No terceiro capítulo é que começa o relato propriamente dito: Paulo Honório conta-nos como, de miserável que era, enriqueceu e se apossou da fazenda São Bernardo'. A partir daí, a narrativa toma outro rumo: bem-sucedido em todos os seus planos, Paulo Honório resolve se casar, com o objetivo específico de ter um herdeiro. No entanto, contrariando esse pragmatismo inicial, o fazendeiro interessa-se por Madalena, uma professora com idéias e modos bem diferentes dos seus. O casamento se realiza e o filho nasce, mas Paulo Honório não consegue se entender com Madalena. Ela não aceita o processo de reificação a que o marido submete todos que o cercam. Ele não aceita o julgamento que Madalena faz de seus atos.

É sobre esse desentendimento que se desenvolve boa parte da narrativa. Para compreendê-lo, é necessário, antes de mais nada, entender em que bases se estabelece a relação entre Madalena e Paulo Honório. Se, por um lado, Madalena não deixa de ser mais um objeto de conquista dentro do desejo de posse que move Paulo Honório, por outro lado, a relação que se constrói entre os dois é mais complexa.

Embora o processo seja o mesmo ${ }^{2}$, os valores que encerram a conquista de São Bernardo e a conquista de Madalena - nunca inteiramente consumada - são totalmente opostos. São Bernardo representa a desumanização de Paulo Honório. Madalena, a sua humanização. É o amor, esse momento de exceção, a perdição de Paulo Honório (segundo seu próprio ponto de vista) ou sua salvação (segundo o ponto de vista de Madalena).

1 Em "O fator econômico no romance brasileiro", Graciliano critica o desinteresse dos romancistas brasileiros em mostrar a produção de riqueza. Diz ele: "Está claro que os autores não conseguem furtar-se a algumas explicações referentes a este assunto, mas fazem-no como quem toca em matéria desagradável, percebemos que eles se repugnam e não querem deter-se em minúcias. Um cidadão é capitalista. Muito bem. Ficamos sem saber donde lhe veio o capital e de que maneira o utiliza. Outro é agricultor. Não visita as plantaçōes, ignoramos como se entende com os moradores, se a safra lhe deu lucro. [...] Não surpreendemos essas pessoas no ato de criar riqueza. A riqueza surge criada, como nas histórias maravilhosas, faz-nos pensar no deserto, onde o povo eleito recebia alimento do céu" (Ramos, 1980: 254-5). Graciliano observa que é preciso mostrar o homem em sua prática cotidiana (o que faz para viver) para poder mostrar como ele pensa o mundo à sua volta.

2 Como mostra J. L. Lafetá: "Madalena merece destaque especial, pois se transformou no objetivo de Paulo Honório. Assim como procedeu para apropriar-se de São Bernardo, caminhando em linha reta, assim ele procederá agora. (..) É de novo a ação decidida, o gesto oportuno, a rapidez e o conhecimento do instante que tornam Paulo Honório vitorioso. (Lafetá, 1992: 200-1) 
Aliás, o que marca a personagem de Graciliano Ramos de um modo geral é essa eterna não coincidência consigo mesma. Suas personagens são seres divididos; e essa divisão não é apresentada como problema a ser resolvido pela trama, mas como elemento constitutivo (momento de construção) do ser. O que revela o tratamento dialético que Graciliano dá às dicotomias que explora nos (des)encontros culturais e ideológicos que aborda constantemente em sua obra.

A relação identidade/alteridade não se dá assim apenas entre Paulo Honório e Madalena, mas no interior do próprio Paulo Honório, que se modifica com a passagem de Madalena por sua vida ${ }^{3}$ :

"Conforme declarei, Madalena possuía um excelente coração. Descobri nela manifestações de ternura que me sensibilizaram. E, como sabem, não sou homem de sensibilidades. É certo que tenho experimentado mudanças nestes dois últimos anos. Mas isto passa." (Ramos, 1992: 104)

Assim, por mais monolítico que pareça ser, Paulo Honório também apresenta rachaduras. É onde aparecem seus inversos, seus avessos. Como nota Antonio Candido, sobre o julgamento que Paulo Honório faz de si mesmo no final do livro:

"O narrador sente que o homem que ele manifestou para o mundo, e se desumanizou na conquista da fazenda São Bernardo, no domínio sobre os outros, - que esse homem era parte do seu ser, não o seu ser autêntico; mas que o contaminou todo, inclusive a outra parte que não soube trazer à tona e que avulta de repente aos seus olhos espantados, levando-o a desleixar a fazenda, os negócios, os animais, porque tudo "estava fora dele" "(Candido, 1978: 106)

Essa divisão de Paulo Honório que aparece no nível do narrado vai se desdobrar no nível da narração. Isso aparece representado no trecho citado

3 Também no interior de Madalena ocorre essa divisão, embora isso não seja mostrado em detalhe, já que o foco está sempre em Paulo Honório. Um exemplo dessa divisão ocorre entre o que Madalena pensa (vê o mundo pela ótica do explorado) e a sua nova condição (proprietária), que exigiria um outro modo de agir - o que é permanentemente cobrado por Paulo Honório. Deve-se notar que em Madalena a crise entre o Mesmo e o Outro gera uma dissolução. Madalena não consegue conciliar o seu ideal de solidariedade e igualdade com a realidade brutal e desigual que a rodeia. 

Desencontro cultural e ideológico em São Bernardo, de Graciliano Ramos. Língua e Literatura, n. 22, p. 123-135, 1996.

anteriormente através de uma mudança na voz que caracteriza o narrador. Palavras como "coração", "ternura", "sensibilizaram" são raras na boca de Paulo Honório. São expressões de carga emocional que invadem o discurso objetivo ("declarei") que Paulo Honório procura construir. Note-se também que o tom categórico ("não sou" "é certo" "isto passa") desse discurso vacila com uma atenuação: "tenho experimentado mudanças" - e não "mudei", como seria de esperar pela forma direta de dizer as coisas que normalmente Paulo Honório adota em suas falas. É como se Paulo Honório não admitisse a perda de controle, quisesse manter o centro, tomando por transitória a revolução que Madalena iniciou em seu ser, rachando-o ao meio.

Antes, porém, de a transformação se dar em Paulo Honório (tarde demais, Madalena já está morta), as diferenças culturais e ideológicas entre ele e Madalena afloram a todo momento. Não há no livro uma grande discussão, digamos, abstrata entre os dois. Nem seria verossímil. O que temos é a discussão cotidiana, sobre coisas do dia-a-dia, que vai revelando o sistema de idéias que cada um dos dois sustenta. Vejamos como isso se dá.

Carlos Nelson Coutinho observa que Paulo Honório investe na construção de um "pequeno mundo" na fazenda São Bernardo (Coutinho, 1965: $87)^{4}$ Recria o núcleo familiar, tentando superar sua condição de enjeitado; cria uma nova vida, deixando de lado sua origem humilde. Se Paulo Honório não nega o que foi no passado - "arrastei enxada, no eito" (Ramos, 1992: 29), "fui trabalhador alugado" (Ramos, 1992: 111) - é apenas para estabelecer a diferença com o que é no presente: um proprietário. E, em última instância, para marcar a diferença em relação aos miseráveis com que se defronta: Paulo Honório não se considera igual a eles porque conseguiu se transformar.

No fundo, Paulo Honório procura se esquecer de quem foi (miserável, carente). Tudo isso fica do lado de fora do seu mundo, do lado de fora desse NÓS que ele construiu. Assim, Paulo Honório não se reconhece nos miseráveis que trabalham em sua fazenda. Acredita que, ao atravessar a linha que separa a classe subalterna da dominante, adquiriu o direito (e aceitou o dever) do esquecimento. Para Paulo Honório, os trabalhadores de sua fazenda são

4 Deve-se observar, no entanto, que para Carlos Nelson Coutinho a criação desse "pequeno mundo" é marcada pelo egoísmo, não pela afetividade. Há leituras opostas a essa: Candido (1956: 27-8) nota não apenas o afeto de Paulo Honório em relação à velha Margarida mas também o seu amor por Madalena; Lafetá (1992: 199) também vê um Paulo Honório capaz de amar e mostra como efetivamente a narração de Paulo Honório muda de tom (usando diminutivos, por exemplo) quando o assunto é Madalena. 
ELES: aqueles que não participam da cena, aqueles que lhe servem, que lhe são úteis, mas que efetivamente não fazem parte do seu universo particular.

Também pobre na sua origem, Madalena faz o contrário: nunca se esquece de quem foi e identifica a vida dificil dos trabalhadores da fazenda com as privações por que passou. Esse é um dos principais pontos do desentendimento entre Paulo Honório e Madalena: eles discutem o tempo todo sobre quem são, se devem esquecer ou reconhecer uma parte da sua identidade, aquela que diz respeito ao passado de misérias que viveram.

Vejamos os pontos básicos dos discursos de Paulo Honório e de Madalena a respeito desses Outros (os pobres, os subalternos), que em certa medida são eles mesmos. Um trecho que assinala muito bem e de forma bastante condensada o conflito de pontos de vista entre Paulo Honório e Madalena é este:

"[Madalena] Enjoou o Padilha, que achou 'uma alma baixa' . (Aí eu expliquei que a alma dele não tinha importância. Exigia dos meus homens serviços: o resto não me interessava.)" (Ramos, 1992: 95)

Madalena avalia um homem por suas qualidades morais ("alma bai$x a$ "), enquanto Paulo Honório dá valor a um homem por sua capacidade de produção ("serviços"). Essa passagem é a primeira manifestação do desencontro ideológico que se desenvolve entre Paulo Honório e Madalena. Ou ainda: entre um discurso que se sustenta sobre pilares do capitalismo (utilitarismo, valores materiais, justificação da desigualdade) e um discurso de base humanista (solidariedade, valores morais, afirmação da igualdade).

Na seqüência do comentário sobre Padilha, um outro trecho acentua o confronto de idéias entre Paulo Honório e Madalena. É um diálogo entre os dois sobre um outro empregado da fazenda, Mestre Caetano:

“- Outra coisa, continuou Madalena. A família de mestre Caetano está sofrendo privações.

- Já conhece mestre Caetano? perguntei admirado. Privações, é sempre a mesma cantiga. A verdade é que não preciso mais dele. Era melhor cavar a vida fora.

- Doente...

- Devia ter feito economia. São todos assim, imprevidentes. Uma doença qualquer, e é isto: adiantamentos, remédios. Vai-se o lucro todo. 

Desencontro cultural e ideológico em São Bernardo, de Graciliano Ramos. Língua e Literatura, n. 22, p. 123-135, 1996.

- Ele já trabalhou demais. E está tão velho!

- Muito, perdeu a força. Põe a alavanca numa pedra pequena e chama os cavouqueiros para deslocá-la. Não vale os seis mil-réis que recebia. Mas não tem dúvida: mande o que for necessário. Mande meia cuia de farinha, mande uns litros de feijão. É dinheiro perdido." (Ramos, 1992: 96)

Madalena menciona as privações, a doença e a velhice de mestre Caetano para mostrar que ele precisa ser ajudado, pois já trabalhou muito. É um discurso que se situa não numa perspectiva socialista (reformas de base), mas sim numa visão assistencialista: a desigualdade social poderia ser minorada com gestos de boa vontade, através do comprometimento moral dos mais ricos em relação aos mais pobres.

Paulo Honório, por sua vez, desqualifica o primeiro ponto da argumentação de Madalena (privações), sugerindo que já faz caridade ao manter um empregado de que não necessita mais. Ataca o segundo argumento (doença), dizendo que a culpa é do próprio mestre Caetano, que não fez economia. Além disso, Paulo Honório tenta mostrar que é ele próprio a maior vítima, destacando que a doença do empregado traz prejuízos a ele, Paulo Honório ${ }^{6}$ Por fim, concorda quanto à velhice do empregado, mas apenas para seguir um raciocínio totalmente oposto ao de Madalena: mestre Caetano perdeu a força, não vale o seu salário.

A fala de Paulo Honório reproduz na sua essência alguns discursos que procuram justificar a desigualdade social: a culpa da pobreza é dos pobres; a pobreza não é problema meu (no caso, o privilegiado), porque é resultado de um estado de coisas que já está dado, independentemente do que se faça; a pobreza só é problema meu quando me afeta diretamente (no caso de Paulo Honório, as dificuldades de mestre Caetano afetam o seu lucro).

5 Esse discurso também aparece em São Bernardo, mas na fala de outra personagem, Padilha. É o que mostra esta passagem: "Luis Padilha discursando para Marciano e Casimiro Lopes: - Um roubo. É o que tem sido demonstrado categoricamente pelos filósofos e vem nos livros. Vejam: mais de uma légua de terra, casas, mata, açude, gado, tudo de um homem. Não está certo." (Ramos, 1992: 59) Esse discurso, como o de Madalena, é mostrado em oposição ao discurso de Paulo Honório.

6 Esse tipo de inversão é comum no discurso de Paulo Honório, como mostra essa outra passagem: "À noite reuni Marciano e Padilha, na sala de jantar, berrei um sermão cumprido para demonstrar que era eu que trabalhava para eles." (Ramos, 1992:61) 
A idéia de que o mundo já está determinado aparece de forma mais nítida em outra discussão entre Paulo Honório e Madalena. Novamente, o assunto é o tratamento dado a um empregado da fazenda:

"- Bater assim num homem! Que horror!

- Julguei que ela se aborrecesse por outro motivo, pois aquilo era uma frivolidade.

- Ninharia, filha. Está você se afogando em pouca água. Essa gente faz o que se manda, mas não vai sem pancada. $\mathrm{E}$ Marciano não é propriamente um homem.

- Porquê?

- Eu sei lá. Foi vontade de Deus. É um molambo.

- Claro. Você vive a humilhá-lo.

- Protesto! exclamei alterando-me. Quando o conheci, já ele era molambo.

- Provavelmente porque sempre foi tratado a pontapés.

-Qual nada! É molambo porque nasceu molambo." (Ramos, 1992: 110)

Todas essas discussões vão pontuando a polêmica que se trava entre Paulo Honório e Madalena. É preciso notar que a relação entre um e outro é marcada não por um mal-entendido ocasional, mas por um "mal-entendido sistemático" entre duas visões de mundo. Nesse tipo de polêmica, cada um traduz o discurso do outro segundo suas próprias categorias (Maingueneau: 1989:120).

Esse processo de tradução pode ser observado nos exemplos anteriores. Para Madalena (na discussão sobre mestre Caetano), velho significa alguém que, por tudo o que já fez, tem valor e merece respeito; Paulo Honório traduz esse termo como alguém sem valor, um inútil, já que perdeu a força para trabalhar. O mesmo procedimento acontece quando discutem o espancamento de Marciano. A argumentação de Madalena é que um homem não pode ser tratado daquela forma. Paulo Honório não discute o espancamento em si, mas o pressuposto de Madalena: Marciano é um homem. Paulo Honório novamente faz uma tradução: Marciano é um "molambo", é uma criatura que pertence a uma outra categoria, não propriamente humana. Logo, pode ser espancado. Novamente, temos um discurso que tenta explicar a desigualdade: existe um NÓS - aqueles que têm direitos, que merecem respeito - e um ELES, aqueles que têm deveres, que não são levados em conta. 

Desencontro cultural e ideológico em São Bernardo, de Graciliano Ramos. Língua e Literatura, n. 22, p. 123-135, 1996.

Procuramos examinar aqui como o desencontro ideológico entre Paulo Honório e Madalena é representado em São Bernardo. Nesse livro, como em outros romances de Graciliano Ramos, um discurso não é mostrado de forma isolada, mas em relação com outros discursos, numa atividade de interação viva, num processo de mútuo reconhecimento e esclarecimento das distâncias que os separam. É o diálogo social que alimenta o discurso, pois cada enunciador parte dos termos do enunciado alheio para defender sua própria posição. Graciliano Ramos parecia compreender isso, pois procurava captar discursos de grande penetração social e trabalhava sobre eles numa construção polifônica do discurso romanesco. Nesse sentido, parece valer para esse autor a observação que Mikhail Bakhtin faz sobre Dostoiévski:

"Dostoiévski tem o dom genial de auscultar o diálogo de sua época ou, em termos mais precisos, auscultar a sua época como um grande diálogo, de captar nela não só vozes isoladas mas antes de tudo as relações dialógicas entre as vozes, a interação dialógica entre elas" (Bakhtin, 1981: 75)

Faremos ainda uma última observação: São Bernardo trata do desencontro que ocorre entre duas pessoas bastante diferentes. Esse desencontro é de três naturezas: amorosa, cultural e ideológica. Graciliano Ramos usa o amor para dialeticizar a figura de Paulo Honório, sempre tão seguro de si que chega a parecer impermeável ao pensamento alheio ${ }^{7}$ Paulo Honório constrói uma sólida muralha entre ele e os outros. É o amor que abre nessa rocha uma fenda, permitindo a Paulo Honório ouvir o que os outros têm a dizer (ainda que o sentido compartilhado não seja o mesmo).

Por sua vez, o desencontro cultural é marcado pela diferença entre o ponto de vista do sujeito intelectualizado (Madalena) - que partilhou, através da leitura, de experiências e realidades diferentes da sua e, por isso, trabalha com categorias mais abstratas e gerais ao captar o mundo - e o ponto de vista de um sujeito pouco letrado (Paulo Honório), que tira seu conhecimento de mundo do contato direto, vivencial com a realidade que o

7 Paulo Honório está acostumado a impor aos outros a sua concepção de mundo, de forma pronta, sem esperar ou desejar qualquer participação alheia num sentido que ele julga já construído. Veja, por exemplo, como Paulo Honório considera Gondim: "Eu por mim, entusiasmado com o assunto, esquecia constantemente a natureza do Gondim e chegava a considerá-lo uma espécie de folha de papel destinada a receber as idéias confusas que me fervilhavam na cabeça" (Ramos, 1992: 8). 
cerca. Esse desencontro caracteriza-se, entre outros aspectos, por um conflito de linguagens. É algo diferente do desentendimento ideológico (conflito de discursos). Nesses casos, a dificuldade de comunicação não se estabelece no nível do "não concordo com o que você está falando" mas sim do "não entendo o que você está falando" O ponto máximo desse tipo de incompreensão está registrado no episódio em que Paulo Honório encontra o pedaço de uma carta escrita por Madalena e não consegue decifrar o que está dito ali:

"Defronte do escritório descobri no chão uma folha de prosa, com certeza trazida pelo vento. Apanhei-a e corri a vista, sem interesse, pela bonita letra redonda de Madalena. Francamente, não entendi. Encontrei diversas palavras desconhecidas, outras conhecidas de vista, e a disposição delas, terrivelmente atrapalhada, muito me dificultava a compreensão" (Ramos, 1992: 157)

Paulo Honório não compreende nada: nem que a carta é destinada a ele (pensa que é para um amante), nem que se trata de uma carta de despedida de Madalena, que vai se suicidar. Última tentativa de estabelecer o diálogo, a carta acaba revelando justamente o contrário: a impossibilidade de comunicação.

Deve-se notar que é possível representar a interação comunicativa nas relações marcadas pela diferença (cultural, ideológica) de diversos modos. Pode-se, por exemplo, estilizar as linguagens de cada um baseado num registro do típico (por exemplo, as expressões sertanejas e populares que Paulo Honório usa) ou descer às profundezas das diferenças de sentido (por exemplo, o discurso de tom humanista de Madalena e o discurso de teor capitalista de Paulo Honório). Nesse sentido, Barthes observa:

"Balzac, por exemplo, tem consciência aguda das linguagens sociais; entretanto quando ele as reproduz, enquadra-as, como virtuosismos de linguagem: assim é o jargão de M. de Nucingen, cujo fonetismo é escrupulosamente reproduzido (...); há, entretanto em Balzac, outra mimesis da linguagem, mais interessante, primeiro por ser mais espontânea, depois, por ser mais cultural que social: é a dos códigos de opinião corrente (...)" (Barthes, 1988: 112) 

Desencontro cultural e ideológico em São Bernardo, de Graciliano Ramos. Língua e Literatura, n. 22, p. 123-135, 1996.

É também sobre os "códigos de opinião corrente" que Graciliano Ramos trabalha constantemente, ainda que não deixe de lado a mimesis mais direta de estilos e variantes lingüísticas. Note-se, nesse sentido, a representação da variante sertaneja e de um estilo que poderíamos chamar de fala franca, direta, sem rodeios, para caracterizar Paulo Honório. No entanto, a caracterização seria mais exterior, mais tipificada, se parasse por aí. Representar o diálogo que se estabelece entre discursos de larga difusão social é um modo de inserir a temática do desencontro social num espaço de discussão mais amplo.

De qualquer modo, cada uma dessas formas de representar a interação verbal entre visões de mundo diferentes sugere uma determinada interpretação da relação identidade/alteridade. Assim, num extremo teríamos a apreensão do Outro numa perspectiva exteriozante, que o mostra como uma "fachada" vista a partir dos olhos do Um; no outro extremo teríamos o Outro captado numa perspectiva interiorizante, que o mostra vivo, dinâmico, dentro do contex to da sua concepção de mundo, da sua cultura. Entre uma posição e outra, muitos matizes e combinações, como assinalou em seus trabalhos Mikail Bakhtin.

\section{BIBLIOGRAFIA}

BAKHTIN, Mikhail (1981). Problemas da Poética de Dostoiévski. Rio de Janeiro, Forense-Universitária, $1^{\text {a }}$ edição brasileira.

(1988). "O discurso no romance" In: Questões de literatura e de estética: a teoria do romance. São Paulo, Edusp/Hucitec.

BARTHES, Roland (1988). "A divisão das linguagens" In: O rumor da lingua. São Paulo, Brasiliense, 110-22.

CANDIDO, Antonio. "Ficção e confissão" In: Ramos, G., Caetés (1956). Rio de Janeiro, J. Olympio, p. 13-83. Prefácio.

(1978). "Os bichos do subterrâneo". In: Tese e antítese. São Paulo, Nacional, p. 96-118.

COUTINHO, Carlos Nelson (1965). "Graciliano Ramos" In: BRAYNER, Sonia (org.) (1978). Graciliano Ramos. Rio de Janeiro, civilização Brasileira, $2^{\mathbf{a}}$ ed., col. Fortuna crítica, v. 2.

LAFETÁ, João Luís. "O mundo à revelia" In: Ramos, G. (1992). São Bernardo. Rio de Janeiro, Record, $58^{\mathrm{a}}$ ed., p. 189-213.

MAINGUENEAU, Dominique (1989). Novas tendências em análise do discurso. Campinas, S. P., Pontes.

RAMOS, Graciliano (1992). São Bernardo. Rio, São Paulo, Record. $58^{a}$ edição. 
MARINHO, Maria Celina Novaes. Representação das linguagens sociais no romance:

Desencontro cultural e ideológico em São Bernardo, de Graciliano Ramos. Língua

e Literatura, n. 22, p. 123-135, 1996.

(1982). Cartas. Rio de Janeiro, Record.

(1980). Linhas tortas. Rio, São Paulo, Record, $8^{a}$ edição.

RÉSUMÉ: Dans ce travail, on examine la représentation de l'hétérogénéité discoursive dans le roman. Nous avons pris comme objet de l'analyse le livre São Bernardo, de Graciliano Ramos.

Mots-clés: Bakhtine, roman, dialogisme, hétérogénéité discoursive. 